\title{
Online Gaming Addiction: The Role of Sensation Seeking, Self-Control, Neuroticism, Aggression, State Anxiety, and Trait Anxiety
}

\author{
Mehwash Mehroof, B.Sc. and Mark D. Griffiths, Ph.D.
}

\begin{abstract}
Research into online gaming has steadily increased over the last decade, although relatively little research has examined the relationship between online gaming addiction and personality factors. This study examined the relationship between a number of personality traits (sensation seeking, self-control, aggression, neuroticism, state anxiety, and trait anxiety) and online gaming addiction. Data were collected over a 1-month period using an opportunity sample of 123 university students at an East Midlands university in the United Kingdom. Gamers completed all the online questionnaires. Results of a multiple linear regression indicated that five traits (neuroticism, sensation seeking, trait anxiety, state anxiety, and aggression) displayed significant associations with online gaming addiction. The study suggests that certain personality traits may be important in the acquisition, development, and maintenance of online gaming addiction, although further research is needed to replicate the findings of the present study.
\end{abstract}

\section{Introduction}

$S^{n}$ NCE THE EARLY 2000s, research into online gaming has steadily increased, ${ }^{1-4}$ although relatively little has examined the relationship between online gaming addiction and personality. Gaming addiction (either online or offline) is not as yet an established diagnosis, although further research in the area may contribute toward its inclusion in future editions of the American Psychiatric Association's Diagnostic and Statistical Manual (DSM). Personality traits may play a role in addiction more generally, as many people seem to have personalities that may predispose them to addiction. ${ }^{5}$ One such trait could be sensation seeking. ${ }^{6}$ Although taking risks and experimenting with a variety of activities is considered normal, those who are prone to engage in sensation-seeking behaviors may find themselves at higher risks for developing a dependence on online gaming. However, studies suggesting sensation seeking as an explanation for online gaming addiction are inconsistent. ${ }^{2,7}$ Self-control may also influence online gaming. $\mathrm{Ng}$ and Wiemer-Hastings ${ }^{1}$ stated that since gamers can become easily absorbed in playing, their behavior may lead to a loss of time control. Research by Kim et al. ${ }^{8}$ shows some support for this view. However, there is still a general lack of research on the relationship between self-control and online gaming addiction.
Aggressive traits may also impact online gaming. For instance, Lemmens et al. ${ }^{9}$ reported that excessive adolescent male gamers were more attracted to violent video games than non-violent ones. Other research has also shown a link between excessive gaming and a liking for game violence. ${ }^{10-13}$ Neuroticism is a trait that shows a person to have an overall anxious predisposition and tendency to worry. This is observed in studies suggesting that online games have a negative impact on well-being and that neurotic individuals are more likely than nonneurotic individuals to be addicted to online games. ${ }^{14-17}$

The aim of this study was to further investigate the roles of various personality traits and their associations with online gaming addiction in a university student sample. Kandell ${ }^{18}$ noted that university students were more vulnerable to excessive Internet use in comparison to any other groups because of their flexible time schedules, being away from home for the first time, and so on. More specifically, this study examines sensation seeking, self-control, aggression, and neuroticism and their relationship with online gaming addiction. It also considers the role of both state and trait anxiety in relation to online gaming addiction, because there are clear differences between the temporary condition of state anxiety and the more general and long-standing quality of trait anxiety. 


\section{Method}

\section{Participants}

Data were collected over a 1-month period using an opportunity sample of university students at an East Midlands university in the United Kingdom. Over 200 students participated, but only 123 participants completed all the questionnaires (72 males, 51 females). The mean age for male participants was 22.3 years $(S D=2.1$ years), and for female participants, it was 21.6 years $(S D=3.0$ years).

\section{Materials}

The survey comprised a battery of questionnaires including the Game Addiction Scale, ${ }^{19}$ the Self-Control Scale, ${ }^{20}$ the Buss-Perry Aggression Questionnaire, ${ }^{21}$ the Inventory of Sensation Seeking, ${ }^{22}$ the State-Trait Anxiety Inventory for Adults, ${ }^{23}$ and the Eysenck Personality Questionnaire (Revised Short Scale). ${ }^{24}$ Additionally, there were two demographic questions regarding gender and age.

Game Addiction Scale (GAS). Lemmens et al. ${ }^{19}$ developed the GAS to measure computer and video game addiction. It contains 21 questions with seven subscales relating to salience, tolerance, mood modification, relapse, withdrawal, conflict, and problems. Each statement is scored on a 5-point Likert scale (1, never, to 5 , very often). The higher the score, the more likely the person is diagnosed as a video game addict. The construct validity of the GAS is found to be significantly high, as both convergent and criterion validity have provided satisfactory correlations with other measures such as time spent on games. These validity tests demonstrate a strong construct validity of the GAS. ${ }^{19}$

Self-Control Scale (SCS). The $\mathrm{SCS}^{20}$ is a 36 -item measure of self-control, including five subscales (discipline, deliberative/nonimpulsive action, health habits, work ethic, and reliability). Each item is scored on a Likert scale (1, not at all, to 5, very much). The higher the score, the higher the individual's self-control. The SCS is validated against a high number of other scales and inventories, such as the Test of Self-Conscious Affect and the Anger Response Inventory. The scale shows considerably high internal consistency (Cronbach's $\alpha=0.89$ ) as well as a good retest reliability $(\alpha=0.89)$.

Buss Perry aggression questionnaire (BPAQ). The $\mathrm{BPAQ}^{21}$ was used to measure trait aggression. The 29 questions comprise four subscales (physical aggression, assessing the frequency of acting aggressively; verbal aggression, assessing the frequency of behaving verbally aggressively; anger, assessing the emotional component of aggression; and hostility, assessing the cognitive element of aggression such as feelings of ill will and injustice). Participants rate themselves on each statement, on a scale of 1 , extremely uncharacteristic of me, to 7, extremely characteristic of me. The higher the score, the higher the level of aggression. Among young adults, internal consistency alpha coefficients of BPAQ range from 0.72 to 0.85 . Additionally, the BPAQ has test-retest reliability coefficients ranging from 0.72 to 0.80 . Construct validity is supported by other self-report methods of personality traits.
Arnett Inventory of Sensation Seeking (AISS). The AISS $^{22}$ was used to measure sensation seeking. It contains 20 descriptive statements to which participants respond on a 4-point Likert scale (4, describes me very well; 1 , does not describe me at all). Two 10-item subscales measure novelty and intensity. Arnett ${ }^{22}$ reports a reliability of 0.70 for the total scale and similar reliabilities for the subscales. Test-retest reliabilities of the AISS items reported an average of 0.80 and above, and internal reliability was reported to be 0.70 . Internal reliability for the subscale intensity is demonstrated to be 0.64 , and 0.50 for the novelty subscale.

State-Trait Anxiety Inventory for Adults (STAI). Spielberger and colleagues ${ }^{23}$ developed the STAI, which contains 40 items divided into two sections of 20 questions and examines state anxiety and trait anxiety. It evaluates how respondents felt at a particular time in the recent past and how they generally feel at the present time. The higher the score, the greater the anxiety. The STAI demonstrates high construct validity for both state and trait anxiety. Test-retest reliability correlations for trait-anxiety are high, ranging from Cronbach's alpha of 0.73 to 0.86 . For state trait-anxiety, it has a reasonable reliability coefficient of 0.62 .

Eysenck Personality Questionnaire (Revised Short Scale) (EPQ-R-S). The EPQ-R-S ${ }^{24}$ comprises 48 items (12 for each of the traits of neuroticism, extraversion, and psychoticism and 12 for the lie scale). It is assessed on a 2-point scale (yes and no). The 12 items from the neuroticism scale have been used to assess emotional stability. Individuals who score higher than 6 on the neuroticism scale are deemed emotionally reactive and have a tendency to display negative emotions such as anger. Cronbach's alphas of 0.84 (males) and 0.80 (females) for neuroticism are reported. It has a good testretest reliability ranging from 0.84 to 0.94 for the complete test, and from 0.80 to 0.97 for separate forms. In addition, convergent and concurrent validity was found.

\section{Procedure}

An e-mail with a link to an online survey was sent out to approximately 500 students asking for online gamers to participate in a survey. It was estimated that up to $50 \%$ of those contacted would have played online games. Participants were instructed to read the background of the study that explained the aims of the research and nature of participating. In relation to the Game Addiction Scale questions, participants were asked to respond in relation to their online gaming behavior only. Given the length of questionnaire, the survey took up to 30 minutes for participants to complete. Once the survey was completed, the participants pressed Send, and the data were automatically coded for SPSS data analysis. In all instances where missing data values occurred, a participant's data were removed, reducing the final sample from over 200 to 123 participants.

\section{Results}

Mean scores by participants on each of the seven scales are reported in Table 1 . The mean score for online video game addiction on the GAS was 61.6 (of a possible 105). This indicates moderately high levels of online video game playing, although scores ranged right across the scale. The mean score 
Table 1. Mean Scores by Participants on Each of the Seven Scales $(N=123)$

\begin{tabular}{lcr}
\hline $\begin{array}{l}\text { Construct measured } \\
\text { (scale used) }\end{array}$ & $\begin{array}{c}\text { Mean (and maximum } \\
\text { score possible) }\end{array}$ & $\begin{array}{c}\text { Standard } \\
\text { deviation }\end{array}$ \\
\hline Game addiction (GAS) & 61.6 (of 105) & 24.1 \\
Neuroticism (EPQ-R-S) & 7.1 (of 12) & 2.9 \\
Self-control (SCS) & 112 (of 180) & 16.7 \\
Sensation seeking (AISS) & 46.3 (of 80) & 6.8 \\
Trait-Anxiety (STAI) & 50 (of 80) & 5.3 \\
State-Anxiety (STAI) & 52.1 (of 80) & 6.6 \\
Aggression (BPAQ) & 103 (of 203) & 24.6 \\
\hline
\end{tabular}

for aggression on the BPAQ was 103 (of 203). This shows that the participants were averagely aggressive, but again there was a high degree of variance in scores across the sample. Scoring on self-control was also modest, as the mean score was 112 (of 180), indicating participants showed they had reasonable control over their behavior. Mean scores for trait and state anxiety were 50 and 52.1 (of 80) respectively. This indicated that participants felt generally anxious, although there was some variance across the sample. Overall, participants were slightly more neurotic than not, as the mean score on the on the EPQ-R-S was 7.1 (of 12). A similar profile was found for sensation seeking with the mean score on the AISS being 46.3 (of 80 ).

A multiple linear regression was performed. No correlations were above 0.9 , so assumptions of colinearity were not violated. The association between video game addiction and predictive variables were strongly positive (multiple $R=0.73$ ). Together, aggression, self-control, anxiety, neuroticism, and sensation seeking accounted for $50.1 \%$ of the variance in online video game addiction scores. Among the predictor variables, five were significant: neuroticism, sensation seeking, state anxiety, trait anxiety, and aggression. The explained variability was also significant, $F(6,116)=21.4$; $p<0.001$.

Results of the multiple regression analysis indicated that five traits displayed significant associations with online video game addiction: neuroticism, sensation seeking, trait anxiety, state anxiety, and aggression. The strongest predictors were state anxiety $(\beta=0.28 ; p<0.001)$ and sensation seeking $(\beta=-0.29 ; p<0.001)$. Self-control $(\beta=-0.11 ; p>0.05)$ had the least impact on online gaming addiction (see Table 2). These results appear to indicate that personality traits contribute to addiction in online video games.

\section{Discussion}

The present study examined the role of various personality traits and their relationship with online gaming addiction. Results demonstrated significant relationships between online gambling addiction and the traits of aggression, sensation seeking, trait anxiety, state anxiety, and neuroticism. Consistent with the literature, sensation seeking was positively correlated with online gaming addiction scores, perhaps because sensation seeking provides a coping mechanism for individuals to overcome their boredom, ${ }^{25}$ and/or online games provide psychological and/or physiological stimulation and rewards for sensation seekers. Given that a variety of reward mechanisms underlie addictive behavior, it is per-
Table 2. Multiple Regression Analysis of Personality Traits and Online Game Addiction $(N=123)$

\begin{tabular}{|c|c|c|c|c|c|}
\hline & $\beta$ & $\begin{array}{c}\text { Standard } \\
\text { error }\end{array}$ & $\begin{array}{l}\text { Standard } \\
\text { coefficient }\end{array}$ & $t$ & $\mathrm{p}$ \\
\hline (Constant) & 73 & 24.5 & - & 2.98 & 0.01 \\
\hline Neuroticism & $2.04^{*}$ & 0.63 & 0.24 & 3.24 & 0.01 \\
\hline Self-control & -0.02 & 0.12 & -0.011 & -0.14 & 0.89 \\
\hline Sensation seeking & $-1.04^{* *}$ & 0.26 & -0.29 & -4.05 & 0.001 \\
\hline Trait anxiety & $1.03^{*}$ & 0.35 & 0.23 & 2.92 & 0.01 \\
\hline State anxiety & $1.03^{* *}$ & 0.28 & 0.28 & 3.74 & 0.001 \\
\hline Aggression & $0.21^{*}$ & 0.081 & 0.21 & 2.58 & 0.01 \\
\hline
\end{tabular}

*Significant at the 0.01 level.

**Significant at the 0.001 level.

haps unsurprising that there was a significant positive relationship between sensation seeking and gaming addiction.

The positive association between aggression and online gaming addiction suggests that aggressive behavior may facilitate the development of online gaming addiction. A number of studies have shown that young males prefer to play violent games rather than nonviolent ones both online and offline. ${ }^{9-13}$ Like sensation seeking, if the game violence is rewarding to those playing, it suggests that the behavior will be repeated and, in some individuals, will lead to excessive and/or addictive play. A study by Ko et al. ${ }^{13}$ showed that higher levels of aggression are related to the behavior becoming goal directed as individuals gain rewards such as a high score. Therefore, it may be that the gamers in this study adopted a goal-driven attitude generated by aggressive tendencies for accomplishment of goals through online gaming.

Trait and state anxiety were both significantly associated with online gaming addiction scores, suggesting that both internal and external anxiety factors encourage excessive online gaming (although state anxiety scores were more highly correlated than trait anxiety). This may be because some university students are faced with temporary unpleasant emotional arousal stemming from high workload. In order to decrease such anxieties, students may use online gaming as a coping strategy to reduce tension (i.e., as a mood modifier). ${ }^{5}$ Likewise, the finding that neuroticism was significantly associated with online gaming addiction is consistent with previous research and suggests another type of coping strategy. For instance, Chen et al. ${ }^{16}$ found that neuroticism displayed a negative relationship with subjective well-being of online game players and argued that neurotic individuals are prone to online gaming addiction. Here, neurotic gamers may be playing as a way of counteracting negative emotions (i.e., neurotic feelings). Predictably, the study found self-control to be negatively correlated with online games addiction, as has been suggested in previous research. ${ }^{8}$

Clearly, the present study has several methodological limitations. The survey was self-report and included a somewhat modest number of gamers all of whom were university students. However, self-report surveys completed online are thought to increase honesty levels, ${ }^{26}$ and the relatively low numbers of participants still produced highly significant results. The fact that all the participants were university students means that the sample was not representative of gamers, 
although demographic studies of gamers suggests that the gamers in this study were not that different from profiles reported elsewhere. ${ }^{27,28}$ The most likely reason for the relatively small number of participants was that the survey took a relatively long time to complete (approximately 30 minutes), and there was no incentive for doing so.

The present study suggests that certain personality traits may be important in the acquisition, development, and maintenance of online gaming addiction. Replication and extension of the findings presented here requires future research. There is also scope to look in depth at relatively unexplored relationships, such as that between excessive online gaming and social anxiety. Factors such as social anxiety may be beneficial to examine, as it may be the case that some gamers lack selfconfidence in social situations and feel more comfortable online. ${ }^{29}$ Online role-playing games may allow individuals to take on the role of different characters within a fantasy world and make people feel less socially anxious.

\section{Disclosure Statement}

No competing financial interests exist.

\section{References}

1. $\mathrm{Ng} \mathrm{B}$, Wiemer-Hastings P. Addiction to the Internet and online gaming. CyberPsychology \& Behavior 2005; 8:110-3.

2. Wan C, Chiou W. Psychological motives and online games addiction: a test of flow theory and humanistic needs theory for Taiwanese. CyberPsychology \& Behavior 2006; 9:317-24.

3. Chappell D, Eatough V, Davies MNO, et al. Everquest-it's just a computer game, right? An interpretative phenomenological analysis of online gaming addiction. International Journal of Mental Health \& Addiction 2006; 4:205-16.

4. Hussain Z, Griffiths MD. Excessive use of massively multiplayer online role-playing games: a pilot study. International Journal of Mental Health \& Addiction 2009. DOI 10.1007/ s11469-009-9202-8.

5. Griffiths MD. (2009) The psychology of addictive behaviour. In Clark L, Meldrum C, Waddely A, et al., eds. Psychology for A2 Level. London: Harper Collins, pp. 436-71.

6. Zuckerman M. (1994) Behavioural expressions and biosocial bases of sensation-seeking. Cambridge: Cambridge University Press.

7. Lavin M, Marvin K, McLarney A, et al. Sensation seeking and collegiate vulnerability to Internet dependence. CyberPsychology \& Behavior 1999; 2:425-30.

8. Kim EJ, Namkoong K, Ku T, et al. The relationship between online game addiction and aggression, self-control and narcissistic personality traits. European Psychiatry 2008; 23: 212-8.

9. Lemmens JS, Bushman BJ, Konijn EA. The appeal of violent video games to lower educated aggressive adolescent boys from two countries. CyberPsychology \& Behavior 2006; 9: $638-41$.

10. Griffiths MD, Hunt N. Computer game playing in adolescence: prevalence and demographic indicators. Journal of Community \& Applied Social Psychology 1995; 5:189-93.

11. Griffiths MD, Davies MNO, Chappell D. Online computer gaming: a comparison of adolescent and adult gamers. Journal of Adolescence 2004; 27:87-96.

12. Grüsser SM, Thalemann R, Griffiths MD. Excessive computer game playing: evidence for addiction and aggression? CyberPsychology \& Behavior 2007; 10:290-2.
13. Ko C, Yen J, Liu S, et al. The associations between aggressive behaviors and Internet addiction and online activities in adolescents. Journal of Adolescent Health 2009; 6:1-8.

14. Biao-Bin V, Man-Na H, Bi-Qun Q, et al. Relationship between Internet behavior and subjective well-being of teenagers. Chinese Journal of Clinical Psychology 2006; 14:68-9.

15. Chen LS. Subjective well-being: evidence from the different personality traits of online game teenager players. CyberPsychology \& Behavior 2008; 11:579-81.

16. Chen LS, Tu HH, Wang ES. Personality traits and life satisfaction among online game players. CyberPsychology \& Behavior 2008; 11:145-9.

17. Huh S, Bowman ND. Perception and addiction of online games as a function of personality traits. Journal of Media Psychology 2009; 13.

18. Kandell J. Internet addiction on campus - the vulnerability of college students. CyberPsychology \& Behavior 1998; 1: 46-59.

19. Lemmens JS, Valkenburg PM, Peter J. Development and validation of a game addiction scale for adolescents. Media Psychology 2009; 12:77-95.

20. Tangney PJ Baumeister RF, Boone AL. High self-control predicts good adjustment, less pathology, better grades, and interpersonal success. Journal of Personality 2004; 72: 272-322.

21. Buss AH, Perry M. The Aggression Questionnaire. Journal of Personality \& Social Psychology 1992; 63:452-9.

22. Arnett J. Sensation seeking: a new conceptualization and a new scale. Personality \& Individual Differences 1994; 16 : 289-96.

23. Spielberger CD, Gorsuch RL, Lushene R, et al. (1983) Manual for the State-Trait Anxiety Inventory Palo Alto, CA: Consulting Psychologists Press.

24. Eysenck SBG, Eysenck HJ, Barrett P. A revised version of the psychoticism scale. Personality \& Individual Differences 1985; 6:21-9.

25. Chiu SI, Lee JZ, Huang DH. Video game addiction in children and teenagers in Taiwan. CyberPsychology \& Behavior 2004; 7:571-81.

26. Wood RTA, Griffiths MD, Eatough V. Online data collection from videogame players: methodological issues. CyberPsychology \& Behavior 2004; 7:511-8.

27. Griffiths MD, Davies MNO, Chappell D. Breaking the stereotype: the case of online gaming. CyberPsychology \& Behavior 2003; 6:81-91.

28. Griffiths MD, Davies MNO, Chappell D. Demographic factors and playing variables in online computer gaming. CyberPsychology \& Behavior 2004; 7:479-87.

29. Cole H, Griffiths MD. Social interactions in massively multiplayer online role-playing gamers. CyberPsychology \& Behavior 2007; 10:575-83.

Address correspondence to: Dr. Mark D. Griffiths Psychology Division Department of Social Sciences Nottingham Trent University Burton Street Nottingham, NG1 4BU United Kingdom

E-mail: mark.griffiths@ntu.ac.uk 